\title{
El COLOR DE LA Piel en la CONSTRucción DE LA IDENTIDAD CUBANA
}

\author{
José María Aguilera Manzano* \\ aguilerajm@unican.es
}

Resumen: El objetivo de este artículo es explicar algunas de las características del proyecto de identidad construido por el grupo de liberales autonomistas cubanos durante el siglo XIX. Esta facción estaba compuesta por intelectuales y miembros de la oligarquía azucarera habanera. Su propósito fue buscar un encaje más ventajoso para la isla de Cuba y los territorios de Ultramar en el marco del estado liberal español en construcción a lo largo del siglo XIX. Debido a la censura, este grupo no pudo usar el discurso político para conseguir este objetivo, lo cual hizo que tuvieran que buscar un camino alternativo para expresar sus ideas; la literatura se convirtió así en su principal instrumento.

Palabras-Clave: literatura, Cuba, esclavitud, autonomismo, identidad

INTRODUCCIÓN

La historia de los imperios, durante la transición del Antiguo Régimen al liberalismo, ha sido escrita por una historiografía que considera que los estados fueron construidos por grupos de poder metropolitanos desde sus metrópolis (MARX, 1970; WEBER, 1985; WALLERSTEIN, 1974). Sin embargo, a lo largo de las últimas décadas, se ha puesto de manifiesto cómo, en los procesos de ensamblaje de los estados en el siglo XIX, las elites de poder de las llamadas "periferias coloniales" se enfrentaron a los proyectos estatales que los reducían a la categoría de colonias, y trataron de conseguir una situación más ventajosa para sus territorios (CHATTERJEE, 2000: 1537-1541; PRAKASH, 1994: 1475-1490; SAID, 2004; COOPER, 2005: 3-54;

* Professor en la Universidad de Cantabria, España. 
DANIELS y KENNEDY, 2002: 2-15). Este artículo se enmarca en el seno de este debate y trata de clarificar la forma en que se asentaron los cimientos de un proyecto "identitario" cubano, que dio unidad a una región del Imperio español, la isla de Cuba, que hasta entonces carecía de ella. Este entramado cultural fue elaborado por un grupo de intelectuales que contaban con el respaldo de una parte de la oligarquía azucarera habanera. Su objetivo fue buscar un encaje más ventajoso para la isla de Cuba en el marco del estado liberal español en construcción a lo largo de la centuria decimonónica. Lo novedoso de esta investigación está en que profundiza en el conocimiento de ese proceso a través del estudio de una obra literaria, Cecilia Valdés, escrita en 1838 por el autor de origen cubano Cirilo Villaverde.

Para llevar a cabo este estudio es fundamental comprender que el concepto "nación", tal y como hoy lo entendemos, es una construcción de reciente creación en la historia; la historiografía, sin embargo, ha tardado bastante tiempo en aceptar este hecho. Desde el siglo XIX, el término "nación" fue usado para designar a aquellos grupos humanos que creían compartir algunas características culturales. Esto los legitimaba para poseer poder político, es decir, un estado independiente o un gobierno relativamente autónomo dentro de una estructura política más amplia. Pero los estudios sobre la idea de nación y el nacionalismo han cambiado mucho en los últimos cuarenta años. Por entonces Hans Kohn o Carlton Hayes no dudaban de que las naciones fueran realidades naturales, y lo único que se debatía eran sus elementos definitorios (KOHN, 1944; HAYES, 1960). Todo autor se veía obligado a hacer un repaso casi canónico por la raza, la lengua, la religión y el pasado histórico. Hacia 1960 Elie Kedourie observó que los estados, necesitados de la adhesión de la población y, al mismo tiempo, no poder permitir que se debatiese constantemente la identidad cultural en que apoyaban su legitimidad, realizaban un esfuerzo para orientar la voluntad de la población, para educarla. El problema nacional, concluía Kedourie, era una cuestión educativa, y el principal promotor de la educación política era el estado. Plantear el problema así significaba dar una vuelta a los enfoques heredados. En vez de aceptar las identidades nacionales como realidades naturales, comenzaron a verse como creaciones artificiales, movidas por intereses políticos (KEDOURIE, 1960). Todo este camino ha estado jalonado en los últimos treinta años con los estudios fundamentales de Ernest Gellner, Benedict Anderson y Eric Hobsbawm, entre otros (GELLNER, 1998; ANDERSON, 1993; HOBSBAWM, 1992).

Los Subaltern Studies han contribuido, desde principios de la década de 1980, a avanzar en esta dirección. Esta escuela historiográfica ha subrayado la 
historicidad relativa del estado-nación como organización política, y nos ha permitido comprender la historia de los imperios y de las relaciones coloniales desde la perspectiva de los colonizados, a conocer el papel de los grupos de la periferia de los imperios en la construcción de las naciones. En esta misma línea, la comparación entre los distintos modelos de evolución política y entre las propias regiones o territorios de un mismo imperio, propuesta por la "historia comparada", ha servido para relativizar el papel del estado nación y conocer la complejidad interna de estos territorios. Finalmente, al poner el acento en las relaciones entre grupos humanos insertos en "comunidades imaginadas" diferentes, la "historia transnacional" también nos ha permitido alcanzar una visión más compleja de las relaciones internas que se establecieron en el seno de las organizaciones imperiales. Estas no fueron sólo relaciones estructurales polarizadas en estados centrales (colonizadores) y estados periféricos (colonizados), sino entidades que se sustentaban en redes de relación mucho más complejas y que eran de naturaleza económica, social y cultural. Esto nos ha dado la posibilidad de descubrir las distintas voces que se comunicaban en esa relación y los procesos de mestizaje que se produjeron (BLOCH, 1928: 15-50; ESPAGNE y WERNER, 1988).

\section{Cirilo Villaverde y su Obra Cecilia Valdés}

Con esta perspectiva historiográfica como trasfondo, vamos a tratar de explicar el significado de la novela Cecilia Valdés, escrita en 1838. Esta fue la obra más perfecta del autor de origen cubano Cirilo Villaverde, según todos los críticos. Sus trabajos literarios no se centraron sólo en la escritura de poesía sino que, con el tiempo también se interesó por la novela de folletín, a la que consideró un instrumento más útil en la construcción de la identidad (VILLAVERDE, 1882; XIMENO, 1953, p. 133-153; HENRÍQUEZ UREÑA,1978; GRACIA DE ALDRIDGE, 1975, p. 183-199; SAID, 2001, p. 11-34; 167-168). Se inició en este campo escribiendo Excursión a Vuelta Abajo en El Álbum, en entregas mensuales a partir de agosto de 1838 (VILLAVER$\mathrm{DE}, 1838 \mathrm{~A}$ y B). Al año siguiente vieron la luz otros textos suyos: Amores y contratiempos de un guajiro, Una cruz negra, La joven de la flecha de oro, todas insertas en La Cartera Cubana en 1839 (VILLAVERDE, 1839A; 1840; BARRERO, 1981, p. 209-218). En el mismo año publicó, por entregas, la primera versión de Cecilia Valdés en La Siempreviva (VILLAVERDE, 1839B, p. 74-87; FRIOL, 1982, p. 43-52)

En esta última obra, Villaverde nos presenta una trama amorosa protagonizada por la mulata libre Cecilia Valdés y el blanco Leonardo 
Gamboa, basándose en la cual plantea el boceto de la sociedad habanera y cubana que él pretendía llegar a construir. La construcción de este complejo esquema le llevó varios años y, aunque inició la obra en 1839 y entonces la publicó en opúsculos, no la acabó hasta varias décadas después, y lo hizo con el mismo título, pero con el subtítulo "O la Loma del Ángel" (VVAA, 1975, p. 182-207; RIVAS, 1990, p. 170-196). Aunque a fines del siglo XIX la presentaron como una novela en la que se reflejaba la sociedad cubana de esa centuria, sin embargo, realmente fue una recreación de la realidad social que Cirilo Villaverde, igual que Anselmo Suárez, José Jacinto Milanés y otros pretendieron imaginar como el contexto social de esa unidad en proceso de invención llamada Cuba. El autor se inspiró en el mundo que le rodeaba a él y a su clase para escribirla. Por eso situó cronológicamente los acontecimientos que en ella tienen lugar a partir de 1812, haciendo coincidir el nacimiento de su protagonista mulata, Cecilia, con el suyo propio, la hizo moverse por La Habana, una ciudad que conocía bien Villaverde; extendió su argumento hasta 1831, un año después de graduarse en leyes él mismo, y graduado en leyes también era el protagonista masculino de su fábula (VILLAVERDE, 1882, p. 12; ÁLVAREZ GARCÍA, 1984, p. 5-44). El ingenio y cafetal donde se movían sus personajes se situaba en la misma zona donde su familia tenía el suyo, en Pinar del Río, en la parte más occidental de la isla. El escritor realmente había vivido en compañía de todos los actores de su trama, narró sus recuerdos personales en ella poniéndolos en cabeza ajena y al servicio de la oligarquía a la que representó (CASTELLANOS, 1947, p. 3-16; GONZÁLEZ, 1983, p. 53-91; BUENO, 1986, p. 43-67; FERNÁNDEZ VILLAURRUTIA, 1957, p. 31-43; GONZÁLEZ, 1981, p. 84-92; MOREJÓN, 1980, p. 51-61). El propio Domingo del Monte le dijo a José Luis Alfonso que esta novela “...es la de más longue haleine que se ha publicado en La Habana, y fuera de algunas incorrecciones de lenguaje y ciertos resabios de estilo, es lo mejor que en su clase ha producido el ingenio cubano: tiene el mérito particular de presentar un cuadro exacto y animado de las costumbres de la gente suburbana $y$ mulatesca de nuestra población..." (MONTE, 2002, p. 201).

En segundo lugar, este texto literario es una descripción de los principales sectores productivos de la oligarquía habanera: los ingenios y los cafetales y, por primera vez, se introdujo el comercio. Estas actividades económicas de los grupos dominantes sirvieron al escritor para ahondar en la división entre criollos cubanos y peninsulares, a la que se añadieron otra serie de distinciones más concretas. Por supuesto, el racismo asomó en las descripciones de personajes mestizos, por el excesivo cuidado puesto en detectar las mixturas raciales, la repetición de criterios predominantes sobre 
los negros y la exageración de los defectos, la imagen idealizada de una ama de esclavos bondadosa, poco menos que tocada por la gracia divina (Isabel Ilincheta) y su entorno de una esclavitud paternal y dócil (VILLAVERDE, 1882, p. 105-113).

El novelista insistió en describir el supuesto enfrentamiento entre criollos y peninsulares mucho más que antes lo había hecho Francisco Suárez y Romero en su novela Francisco, personalizándolo en el seno mismo de la familia Gamboa. La esposa de Cándido Gamboa, peninsular, era Rosa Sandoval, criolla y madre del rellollo (el nacido en Cuba en segunda o tercera generación) Leonardo. A esto se unía la idea de la mulata, Cecilia, como la que intentaba integrar al mulato y al negro en el concepto de identidad cubana que encarnaba la familia Gamboa. Ella era un objeto sexual a la que se veía como una "segundona", postiza, nunca una igual al blanco y, por tanto, sólo podía llegar a ser amante pero nunca esposa de éste y no formaría parte de esa familia, de esa identidad en construcción; por supuesto, tampoco el negro. El autor quiso que la familia Gamboa representase a la "nación cubana", con todos sus ingredientes (VILLAVERDE, 1882, p. 76, 212-215; BUENO, 1984, p. 51-73; CONNOR, 1994).

La pugna que mantuvieron en toda la obra el hijo y padre, Leonardo y Cándido, tenía connotaciones de rebeldía ante el imperio de la voluntad obtusa del segundo, que encarnaba al mando colonial de la isla frente a los criollos. Para acentuar los criterios criollos de Rosa y Leonardo no faltaron incidentes y recurrencias, muy aprovechadas por el narrador. Al joven se le presentó el excesivo celo de su padre para separarlo de Cecilia como una evidencia más de la prepotencia peninsular, además de sospechar un interés rival en los favores de la mulata (AGUIRRE, 1986: 147-161). También se incluyen incidentes de familia provocados por la presencia de un militar procedente de la metrópoli que pretendía a una de las hermanas de Leonardo, pasando por las discusiones entre Rosa y su marido. El enconado despotismo del mando colonial era una piedra de choque constante para Leonardo Gamboa que ya tenía conciencia de su "criollismo" (GONZÁLEZ, 1983: 31-53).

Rosa Sandoval, aunque se reveló contra Cándido Gamboa, finalmente debió acatar la conducta de su marido y su conducción de la familia con mano tan dura como lo hacía el gobernador con la sociedad de la isla en su conjunto (GONZÁLEZ, 1983, p. 265-270; SÁNCHEZ, 1971, p. 123-134; YOUNG, 1949; KANDIYOTI, 2003, p. 213-235). El marido de Rosa, Cándido, era un andaluz enriquecido en gestiones comerciales y es dibujado por el narrador como un hombre con poca cultura y muchas mañas, que había hecho caudal a fuerza de industria y de economía, especialmente a través de 
la trata de esclavos (GONZÁLEZ, 1983, p. 31-36; SÁNCHEZ, 1971, p. 123 134; TORRIENTE, 1946; YOUNG, 1949). Su matrimonio, que benefició al peninsular en cuestión de dote, fue motivo constante de querellas maritales que representaban los enfrentamientos entre los naturales de la isla y de la península:

...Que a usted le pesa ya haberse casado conmigo [le dijo Cándido a su esposa]. ¿Hubiera usted preferido a un criollo jugador y botarate? Por supuesto [le contestó ella]. Tal vez, repuso doña Rosa con mayor suavidad de tono mientras más punzantes eran sus palabras, pero jugador o no, es probable que el criollo, paisano mío, se hubiera portado conmigo con más lealtad y decencia... (VILLAVERDE, 1882, p. 110).

Cándido Gamboa es descrito más como hombre de negocios que de sociedad. Así, mientras Rosa llevaba al baile de la Filarmónica a sus hijas, él asistía a una junta de hacendados y nunca lo vemos sino en transacciones económicas, en el ingenio, o en sus furtivas visitas a la casa de Cecilia. Con escasa cultura, había llegado a la isla de Cuba desde la Serranía de Ronda. Su vinculación con los norteamericanos le permitió ser de los primeros en adquirir veleros rápidos para burlar el cerco inglés en tiempos de la trata clandestina (VILLAVERDE, 1882, p. 110-113; 192-193; LAMORE, 1978, p. 41-52). A pesar de las divergencias que podemos observar en la casa de Gamboa, la autoridad del padre se impugnaba pero se mantenía, igual que la del capitán general (VILLAVERDE, 1882, p. 121).

Villaverde también incluye a un militar peninsular que cortejaba a la hija de la familia y nos presenta a un Leonardo que llevado a su mundo de picardía no le hacía gracia que un castrense le "soplase" a su hermana. Esto avivaba el doble odio que le inspiraba éste en su doble carácter de soldado y peninsular. El ejemplo también le sirvió como excusa al autor para, a continuación, poner de manifiesto la gran cantidad de combatientes peninsulares procedentes del continente que recibía el territorio cubano en esos momentos y que eran causa de conflicto y lucha. A las tropas que se retiraban de Florida, México, América central y del sur le seguían numerosas personas que emigraban de aquellas regiones al ser afectados sus intereses por los gobiernos de las nuevas repúblicas y todos pasaban por la isla de Cuba y a todos los identificaba un sentimiento de odio contra el enemigo victorioso, "el criollo"; aunque en su resentimiento incluían también a la metrópoli al hacerla responsable del fracaso por la mala conducción de la campaña. La avalancha de civiles y tropas produjo problemas de carácter 
público y financiero a la ya populosa Habana, lo cual fue causa de malestar en la población (VILLAVERDE, 1882, p. 104-105, 116, 192-193; Archivo General de Inidas (en adelante AGI), Cuba, 761B; AGI, Cuba, 763; AGI, Cuba, 773; AGI, Cuba, 774; AGI, Cuba, 775; AGI, Cuba, 776; AGI, Cuba, 2057; AGI, Ultramar, 138; AGI, Ultramar, 139; KUETHE, 1986; MORENO FRAGINALS, 1983, p. 34-37; NAVARRO GARCÍA, 1991, p. 273-276). El distanciamiento y hostilidad hacia los peninsulares se agravó con la prepotencia de las autoridades, pareja a su incapacidad para hallar soluciones a los múltiples conflictos que existían en esta ciudad. Todo esto constituía el trasfondo del recelo de Leonardo Gamboa (GONZÁLEZ, 1983, p. 265-294).

Esta conciencia burguesa, donde el dinero daba el estatus social, se contradecía con la lucha por conseguir un título nobiliario por parte de las familias hacendadas. Por un largo periodo de tiempo, la adquisición de rango de nobleza aminoró la distancia entre criollos y peninsulares y tendió un puente por el cual disminuir la preeminencia aristocrática peninsular. El mantenimiento de un título era difícil pues después de comprado había que abonar todos los años una serie de impuestos igualmente elevados. En la novela, la familia Gamboa estaba a la espera de un título tramitado a las cortes. Conquistado el poder económico y demostrada la eficacia empresarial, la nobleza calzaba la riqueza y le daba una valoración clasista (VILLAVERDE, 1882, p. 122; GONZÁLEZ, 1983, p. 265-299).

A las puertas de ese mundo de blancos, pero fuera de él y, por tanto, también del concepto de identidad en construcción, quedó el mulato, representado en la obra por Cecilia Valdés que sintetizaba las concepciones despectivas hacia este "grupo híbrido" a lo que se unía su condición de mujer (HERNÁNDEZ AZARET, sin fecha; BARRERA, 1979; BUENO, 1963, p. 105-122; COULTHARD, 1958). Cecilia asumió, desde su razón de personaje literario, la manipulación sexista y cuanto de malo para la sociedad liberal endilgaban los blancos a las mulatas, es decir, peligro para los matrimonios establecidos, seducción y pérdida del sentido para el hombre blanco, ser capaz de atraer por su sensualidad, posibilidad siempre latente de un amor advenedizo que se deseaba disfrutar pero no se apreciaba para matrimonio: “...sólo aceptaba como propio [Cecilia Valdés] el destino junto a hombres de raza blanca o superior, como que era de ellos de quienes podía esperar distinción y goce.... Su abuela, inquieta por el destino y futuro de Cecilia deseaba casarla con un hombre blanco porque: “...blanco, aunque pobre, sirve para marido; negro o mulato, ni el buey de oro.... Cecilia creció asimilando estas ideas y por eso decía: “...de mulato sólo quiero las mantas de seda; de negro sólo los ojos y el cabello..." (VILLAVERDE, 1882, p. 3, 12-15, 101- 
102. STOLCKE, 1992, p. 1-20; GUEVARA, 2006: 105-128; BUENO, 1986, p. 43-68; LEANE, 1975, p. 19-25). La mulata era "buena para la cama pero mala para el casamiento", buena para ponerle la casita en extramuros pero no para llevarla al hogar, era la que "había mejorado la raza", no era negra completamente sino mulata. Esa concepción que expresó Villaverde estaba también presente en José Antonio Saco, en Francisco Arango y Parreño, en Domingo del Monte, etc... e incluso en la forma popular de hablar sobre estas cuestiones, según la cual casarse con blanco era "adelantar" y con negro “atrasar” (GONZÁLEZ, 1983: 369).

Cecilia Valdés tuvo que acudir a sus "atractivos de mujer" como única posibilidad, resignada a las limitaciones que el medio le había impuesto. Ella amó y quiso ser amada, pero su potencialidad sensual impidió que despertara sentimientos duraderos; resultó vencida al empeñarse en un vínculo amoroso prohibido por la sociedad. Leonardo Gamboa la amaba, pero la desconfianza lo acompañó siempre. Su propio padre aceptó que "es bien criada y de vida honesta [...] no ha dado aún que decir" pero existía una razón para sospechar de su moralidad “...es de raza híbrida. No hay que fiarse mucho de su virtud. Es mulata y ya se sabe que hija de gata, ratones mata...”. La atracción de Cecilia, sin embargo, no superaba el ámbito sexual o de la envidia. Hemos de tener en cuenta que la relación con una blanca, en paridad de condiciones, no resultaba cuestión de bromas para aquellos jóvenes ricos, porque llevaba implícitas consideraciones de economía familiar. Esto se puso de manifiesto en todo el ritual que conllevó la oficialización del noviazgo entre Isabel y Leonardo, todo un convenio entre familias, con previsiones y cálculos (YUVAL-DAVIS, 1997). La mulata era considerada por esa sociedad burguesa como un asidero, un paliativo "a los naturales impulsos viriles de los jóvenes blancos ricos”. Por supuesto, la razón esgrimida por Cirilo Villaverde en la publicación definitiva de la obra bastantes años después no fue esta sino el parentesco que existía entre Leonardo y Cecilia. Sin embargo, una comparación con el texto publicado en 1839 en La Siempreviva nos hace decantarnos por la argumentación expuesta.

Todo esto que narra el autor nos condiciona para recibir como lógica la tragedia que dio fin al conflicto de la mulata. El padre de Leonardo, impulsado por su complejo de culpa, hizo que la internaran en la cárcel para prostitutas y el peor elemento del hampa femenina, es decir, la Casa de Recogidas, que se había encargado de poner en marcha la Sociedad Económica de La Habana, institución que encarnó y representó esos valores burgueses casi desde el momento de su fundación a fines del siglo XVIII (GONZÁLEZ, 1983, p. 113-159). 
Villaverde, aunque se negó a admitir a los mulatos dentro de la estructura social que su grupo estaba armando, a diferencia de lo que hizo Anselmo Suárez Romero en Francisco, reconoció en su libro el mestizaje como una realidad de la sociedad cubana. Esta práctica era inevitable por la convivencia del esclavo doméstico con sus amos, atendiéndolos en la intimidad y también en sus actividades sociales. No sólo por eso, sino que los niños blancos eran criados por las esclavas negras, quienes en su lengua bozal les narraban cuentos de su tierra; al hijo del hacendado sus padres le regalaban un muleque, el niño negro que jugaba con él y que tan bien describió el poeta José Jacinto Milanés en una de sus poesías, y con él crecía aunque el blanco era el "señorito" y el negro el "criado". Este mestizaje también se puso de manifiesto en los bailes de cuna, que eran fiestas dadas por mujeres y por eso se le llamaba la cuna de fulana o de mengana, a los cuales acudían y se mezclaban los jóvenes de diferentes "razas" (VILLAVERDE, 1882, p. 31-50, 161-199).

En la fábula también aparece el esclavo negro asociado a dos actividades económicas de la oligarquía: el ingenio y el cafetal. En estos momentos se estaba produciendo una fuerte crítica hacia la trata de esclavos por parte del grupo de escritores en torno a Domingo del Monte y, por tanto, todas las tintas se cargaron contra el ingenio, que era el sector productivo que más los empleaba frente al cafetal, mucho menos duro en este sentido. Por eso, el narrador nos muestra lo felices que eran los negros del cafetal "La Luz" donde se sentían parte de una familia cuyo patriarca era Tomás Ilincheta, pero quien regía de forma bondadosa era su hija Isabel que lo hacía basándose, no en una relación amo-esclavo sino, en una armonía fundada en el temor y respeto a Dios. Frente a ello, nos enseña el infierno que suponía ser esclavo en la plantación cañera "La Tinaja”. Esta actitud de crítica hacia esta práctica no la debemos entender como un acto humanitario sino como simple interés económico. La esclavitud no condicionaba directamente la modernización del sector, como han explicado varios autores, y prueba de ello es que, como mostró Manuel Moreno Fraginals, el beneficio del azúcar produjo notables progresos tecnológicos antes de la abolición de ésta. La dificultad era más compleja pues los hacendados eran conscientes de que, debido a las restricciones impuestas por los ingleses al comercio de negros, el precio de los esclavos no haría sino aumentar, como así ocurrió, comprometiendo tanto los beneficios del negocio así como la exportación del azúcar. Pero además, existía un problema político vinculado a la trata pues el mantenimiento del tráfico generaba una situación de endeudamiento crónico de los hacendados con los comerciantes, que controlaban el negocio 
de la compraventa de esclavos y también una dependencia absoluta de sus circuitos de distribución de mano de obra forzada. Por eso, el autor criticaba al ingenio y alababa al cafetal como una forma de producción no tan dependiente de la mano de obra esclava (GONZÁLEZ, 1983, p. 31-53 y 105-113; MORENO FRAGINALS, 2001, p. 117-125; MORENO FRAGINALS, 2002; DESCHAMPS CHAPEAUX, 1970, p. 24-27; JACKSON, 1976).

Finalmente, Villaverde desarrolló en su novela otro punto enunciado por Anselmo Suárez anteriormente, el uso de la religión como un elemento justificador y mantenedor de ese orden social que él y su grupo querían establecer. Rosa Sandoval aludía con insistencia a los preceptos de la religión católica pues el autor quería ejemplificar en ella las características, a su juicio típicas, de un ama de esclavos a quien la argumentación religiosa le sirvió para amparar la explotación de la plantación y la trata. En este mundo la religión se entendía como instrumento de poder y compulsión ideológica en un entorno de agudas desigualdades. Rosa Sandoval no dudó en rodear su figura de un aura casi divina frente a quienes la sojuzgaban pues ella personifica al amo-dios, capaz de castigar con furia, pero sensible e indulgente cuando se le solicitaba con sumisión (HERNÁNDEZ AZARET, 1983; CALLAHAN, 1989). El "practicismo" a que llegó el catolicismo en el emporio azucarero quedó ejemplificado en la Explicación de la doctrina cristiana acomodada a la capacidad de los negros bozales, una obra de Antonio Duque Estrada, editada en la imprenta de Severino Boloña en 1823. Su objetivo era, sin rodeos, atenuar la rebeldía del negro y justificar los rigores del régimen esclavista. Una de sus partes decía "Dios me hizo esclavo, él quiere que yo sirva a mi amo, pues voy a trabajar porque Dios quiere..." (Véase carta de Domingo del Monte a José Luis Alfonso, La Habana 2 de diciembre de 1839, en Biblioteca Nacional José Martí, Sala cubana, Monte; GONZÁLEZ, 1983, p. 228-265).

\section{El Proceso de Elaboración de un Canal Literario}

La obra de Cirilo Villaverde, junto al drama El Conde Alarcos, de José Jacinto Milanés, Francisco, de Anselmo Suárez Romero, y Matanzas y Yumurí, de Ramón de Palma, son la expresión más acabada del concepto de identidad que estaba creando el grupo de intelectuales que rodeaban a Domingo del Monte. Estos textos fueron posibles gracias a todo un proceso de maduración iniciado algunos años antes (MILANÉS, 1965: 134-157; SUÁREZ ROMERO, 1880; PALMA, 1837).

En la primera mitad del siglo XIX se produjo el tránsito del Antiguo Régimen al sistema liberal en el Imperio español. La corona, arrastrada por 
las circunstancias, se vio obligada a reconvertir el territorio peninsular en un estado nacional al estilo del francés. Esta idea tomó más fuerza a partir de la llegada de las tropas de Napoleón Bonaparte a la península en 1808, la redacción de la Constitución de Cádiz de 1812 y posteriormente, tras el reestablecimiento del absolutismo entre 1814 y 1820 , durante la vuelta al liberalismo entre esta última fecha y 1823 (FONTANA, 1979; FONTANA, 1971). Al mismo tiempo que se producían estas transformaciones en la metrópoli, los distintos gobiernos tuvieron que plantearse qué papel jugaban los dominios americanos en el naciente estado español. La mayoría de los liberales peninsulares, y una parte de la elite de La Habana, se fueron decantando por no insertar a los territorios de Ultramar dentro del proceso de formación del estado liberal, y darles una categoría inferior políticamente a través de la legislación, porque de hecho ya era así (FRADERA, 2005; FRADERA, 1999). Paralelamente a esta acción política, desde la península, se llevó a cabo la difusión de un entramado cultural que pretendía justificar esta operación legislativa. En este segundo aspecto jugaron un papel fundamental las sociedades económicas y para el caso cubano, específicamente, la Sociedad Económica de La Habana, que fue constituida como órgano difusor del proyecto identitario gubernativo (AGUILERA MANZANO, 2005).

Sin embargo, este plan encontró muchos obstáculos en su camino, pues durante la década de 1820 La Habana se había convertido en uno de los centros económicos más importantes del Imperio español, liderando esta riqueza el sector de hacendados al frente del cual estaba Francisco Arango y Parreño, y en el que se integraban las familias Aldama, Alfonso y Soler. En poco tiempo quisieron que su peso económico se correspondiera con el liderazgo en la sociedad sobre la que estaban asentados, para lo cual intentaron usar el discurso político y la legislación liberal como instrumento, pero esto sólo fue posible hacerlo, de forma muy restringida, durante el periodo comprendido entre la muerte de Fernando VII, a finales de 1833, con la consiguiente restauración del liberalismo, y 1837, en que la isla fue excluida de la estructura liberal en construcción mediante la expulsión de sus diputados de cortes. Por ello, paralelamente también elaboraron un andamiaje cultural que daba fundamento ideológico y completaba a la acción política, y Domingo del Monte fue el encargado de darle forma también a través de la Sociedad Económica. Como los demás, este proyecto liberal no estuvo plenamente armado desde un principio, sino que se fue negociando y modificando a lo largo del tiempo. Su primer objetivo era que las líneas maestras del entramado cultural que construyó fueran imaginadas como las directrices de la cultura española que se estaba estableciendo desde la 
Península Ibérica. Los intentos tuvieron poco éxito y, ante esto, pretendió que, al menos, fuera considerada la de toda la isla de Cuba y se integrase en la metropolitana, como una parte representativa de España, pero peculiar. La negativa a transigir les llevó a definirla como independiente.

En este proceso los distintos grupos liberales emplearon varios instrumentos, entre ellos: primero, la construcción de un entramado educativo que diera legitimidad a los principios del nuevo sistema; segundo, la escritura de la historia de ese nuevo estado con la misma intención y, tercero, la creación de una tradición literaria a través de publicaciones periódica y de una literatura propia. En relación con el tercer punto, Benedict Anderson ha sabido explicar cómo los periódicos y otras publicaciones fueron fundamentales a la hora de crear esas identidades. El boom de la imprenta, el desarrollo del capitalismo impreso, hizo posible la difusión de poesías, novelas y periódicos, que fueron el medio que permitió la representación de lo que él llama "comunidad imaginada". Los periódicos permiten saber a una persona lo que está pasando al mismo tiempo en todos los lugares de esa comunidad, aunque no conozca al resto de individuos que la integran (ANDERSON, 1993; ANDERSON, 1999; ÁLVAREZ JUNCO, 2002).

$\mathrm{Al}$ entrar en contacto con los románticos peninsulares, durante su viaje a la península para graduarse de derecho a finales de la década de 1820, Domingo del Monte aprendió que las publicaciones de tema literario y científico, sabiéndolas conducir por el camino correcto, eran un arma muy eficaz por donde se podía introducir el concepto de cultura que él pretendía, en sustitución del discurso político, prohibido por la censura. De regreso a la isla, del Monte visitó en Estados Unidos a su maestro y filósofo, Félix Varela. Aquí terminó de madurar su pensamiento en relación a la formación del concepto de identidad que interesaba al grupo económico al que representaba, basado en los principios enunciados antes. Para desarrollar el tercer punto, la creación de una tradición literaria a través de publicaciones periódicas y una literatura propia, era necesario, primero, la elaboración de una literatura que expresara las ideas y conceptos que se pretendían transmitir y, segundo, abrir un canal o sistema de difusión de este pensamiento que funcionara con fluidez entre todos los lugares del territorio cubano.

Del Monte constituyó un núcleo de intelectuales que dieron forma literaria a las ideas y el pensamiento a transmitir, cuyo centro radicó, en principio, en torno a los periódicos El Puntero Literario y La Moda o Recreo Semanal del Bello Sexo, subvencionados por la Sociedad Económica, y la publicación de la obra Rimas Americanas (HERRERA DÁVILA, 1833; LLAVERÍAS, 1957; BATISTA VILLAREAL, 1965; VVAA, 1984; BACHILLER, 
MORALES, 1936; JENSEN, 1988). Algún tiempo después dieron forma legal al grupo a través de la puesta en marcha de la Comisión de Literatura y, cuando ésta se disolvió por las presiones de otros grupos liberales, en la tertulia de la casa de del Monte (MARTÍNEZ, 1997; AGUILERA MANZANO, 2005). En estos centros, con sede todos en La Habana, participaron principalmente intelectuales que vivían en esta ciudad o sus alrededores, entre los que destacó Anselmo Suárez Romero, que dieron a conocer sus ideas a través de publicaciones periódicas o libros conjuntos publicados en La Habana, mayoritariamente. El sistema se completaba con la difusión de ese pensamiento por el resto de la isla, para lo cual se valió de la amistad que mantuvo, mediante carta, con algunos de los personajes más ilustrados de las localidades principales, y que generalmente eran miembros de las diputaciones que la Sociedad Económica mantenía en esos lugares. Estos ilustrados reimprimían en los periódicos de sus ciudades las obras que previamente eran impresas en las publicaciones de La Habana y que el grupo de del Monte se encargaba de enviarles por correo. A su vez, estos pensadores locales le enviaban a del Monte a La Habana para publicar las mejores producciones del resto de las principales localidades de la isla, cuando las había. No obstante, esta relación fue desigual y mayor en la dirección que iba desde La Habana hacia el resto de la mayor de las Antillas, con algunas excepciones. Por otro lado, el grupo de La Habana se nutría de las ideas y producciones que le llegaban desde el extranjero, fundamentalmente distintos puntos de Estados Unidos, París, de varias ciudades de la península y, en menor medida, Londres (MONTE, 2002).

Esto lo pudieron realizar porque Domingo del Monte logró penetrar en los órganos de poder de la Sociedad Económica, al ser nombrado secretario de la Sección de Educación de la Sociedad. El grupo quiso ir más allá $\mathrm{y}$, por eso, desde 1829 intentaron poner en marcha una clase de literatura dentro de esta institución, pero se les negó la autorización y en su lugar se permitió la creación de una Comisión Permanente de Literatura, bajo la tutela de la Sección de Educación (Eran miembros de la Comisión Domingo del Monte, Manuel González del Valle, Ignacio Valdés Machuca, Agustín Govantes, Nicolás de Cárdenas y Manzano, Blas Osés y Vicente Osés, Felipe Poey, Prudencio de Hecheverría y O'Gaban y José Antonio Saco (MONTE, 1830; MONTE, 1831). Aunque el experimento de la Comisión de Literatura terminó siendo reprimido en 1834, durante los años que funcionó aportó elementos muy importantes en la formación de un sistema cultural distinto al que se trataba de implantar desde la metrópoli. La Comisión consiguió iniciar la publicación de la Revista Bimestre Cubana, puso en marcha en 1831 
un concurso literario, cuya pretensión era dar a conocer a los jóvenes valores de la isla, y también realizó un Diccionario de los provincialismos cubanos, donde se incluyeron 700 vocablos "propios de Cuba". Además, del Monte consiguió que la Sociedad subvencionara varios periódicos literarios, desde donde también construyó su concepto de identidad: El Puntero Literario y La Moda o Recreo Semanal del Bello Sexo (MARTÍNEZ, 1989; JENSEN, 1988, p. 113-115; PICHARDO, 1849).

Tras el cierre de la Academia de Literatura, Domingo del Monte decidió ir a pasar algún tiempo a los ingenios que los Aldama tenían en Matanzas, donde vivía su propia familia. Allí se reencontró con su amigo Félix Tancó y con José Miguel Angulo. De vuelta en La Habana, organizó unas tertulias con el grupo de pensadores que había formado parte de la Academia de Literatura. Éstas eran una forma de continuar su proyecto de creación cultural de forma privada y, por tanto, mucho menos controlada desde el ámbito oficial. En estas charlas comenzaron a sobresalir las obras escritas por Anselmo Suárez Romero, que llegaban por correo desde el ingenio Surinam, donde él residía, y que eran discutidas y corregidas por otros miembros de la tertulia, como José Zacarías González del Valle, Ramón de Palma, Cirilo Villaverde, Francisco Manzano y Gabriel de la Concepción Valdés (Plácido) (LLAVERÍAS, 1957; CALCAGNO, 1878; VVAA, 1984; BACHILLER Y MORALES, 1936). De hecho, en varias ocasiones, el propio Suárez viajó a La Habana y expuso sus creaciones a los otros miembros de la tertulia, lo que le permitió conocerlos. Durante este periodo, del Monte se centró en su labor de ideólogo desde un segundo plano, dejando la producción de obras al grupo de escritores que lo rodeaba. Aunque se alejó de la Sociedad Económica, todos los textos de esta etapa fueron saliendo a la luz en publicaciones periódicas para las que consiguió subvenciones de esta institución. En 1837 se publicó El Aguinaldo Habanero y entre 1838 y 1840 El Plantel, El Álbum, La Cartera Cubana y La Siempreviva (LLAVERÍAS, 1957; BATISTA VILLAREAL, 1965; VVAA, 1984; BACHILLER Y MORALES, 1936; JENSEN, 1988, p. 123-125).

LA ESTRUCTURACIÓN DE LA IDENTIDAD CULTURAL ATRAVÉS DE LA LITERATURA

Domingo del Monte expuso las líneas generales por donde debía dirigirse la literatura en la construcción identitaria, siempre guiado por los intereses económicos a los que respondía él y su grupo. Esta estructura no estuvo perfectamente definida desde un principio, sino que hubo una evolución en su pensamiento a lo largo del tiempo y, además, sus compañeros y miembros de tertulia la fueron adaptando a medida que las ideas iban 
madurando. En un principio consideró del Monte que la poesía era el género literario más importante, el que permitía describir la realidad como ninguno. Realmente lo escogió porque era el que mejor se adaptaba a sus intenciones, el más ambiguo y el que admitía una mayor diversidad de interpretaciones de lo que el autor quería decir, ya que únicamente se le exigía a éste adaptarse a una métrica determinada para que entrara en esa categoría de poesía; esto le permitía modelar la realidad a su gusto. Sin embargo, por estas mismas características de la poesía, los ataques a este género fueron cada vez mayores, ya que se consideraba que era el que usaban los pueblos en su minoría de edad, el que apelaba más a los sentidos y menos a la razón (MONTE, 1929, 211- 244; GONZÁLEZ, 1983: 92-105; HENRÍQUEZ UREÑA, 1978, 53-67).

Ante esto, del Monte incentivó, no sin cierto recelo, la novela entre los miembros de su tertulia. La escritura en prosa hacía mucho menos ambiguas las interpretaciones que de ella se podían hacer y, además, ésta admitía una trama más compleja en la que se mezclaban más temas, pero este género tampoco exigía ningún apego de los hechos que se narraban a la realidad. En la novela vio del Monte un campo de trabajo muy interesante, si se conseguía darle veracidad histórica, es decir, asentar como reales y ciertos los hechos que se narraban y, en este sentido, la novela histórica se convirtió en un buen instrumento. Este género le permitía la ambigüedad de mezclar realidad y ficción, ya que es parte novela y parte hechos históricos y, por tanto, una herramienta que, usada correctamente, sería perfecta en su intención de interpretar la historia de la isla a favor de los intereses económicos a los que representaba (LAZO, 1965; MITJANS, 1918; ROMERO TOBAR, 1994: 355-370; LLORÉNS, 1989, p. 295-324 y 343-374; BENICHOU, 1968, p. 7-9 y 18-38; BENICHOU, 1981; SAID, 2004: 11-34 y 167-168; LUCKÁCS, 1962; EAGLETON, 1976; WILLIAMS, 1977). Los primeros impulsores de este género fueron Ramón de Palma, que en 1838 escribió en El Álbum las producciones Pascua en San Marcos y El cólera en La Habana, y José Zacarías González del Valle, que dio a la luz Amar o morir y Amor o dinero (PALMA, 1838; GONZÁLEZ DEL VALLE, 1838). José Antonio Echeverría, I.Vivanco, Antonio Bachiller, Anselmo Suárez Romero y Cirilo Villaverde se fueron sumando a los creadores de novelas, aunque de entre todos ellos fue este último el más destacado (MARTÍNEZ, 1997, p. 132-143).

Siguiendo estos principios, a finales de la década de 1820, del Monte había publicado en varios números del Puntero Literario algunas de sus obras, bajo el título "Guirnalda Cubana". Estos poemas, en un principio, tenían como único objetivo la descripción de las características del paisaje de la isla a través de la creación de buenas imágenes (MONTE, 1828). 
Este primer paso, la descripción del paisaje de algunas zonas de la isla, a pesar de su sencillez, era importante en la formación cultural. Hasta ese momento los poetas salidos de Cuba, al escribir en castellano, habían intentado imitar a los peninsulares hasta en las descripciones de las realidades que ellos pintaban, y que eran generalmente las de la metrópoli. En Rimas Americanas, libro donde se editaron las obras poéticas de varios autores, entre los que estaban las de del Monte, se introdujo un nuevo elemento en esta línea de descripción de los campos de la isla: el retrato del paisaje "domesticado" o "culturizado" que daban a la isla determinadas actividades económicas, las de la oligarquía de la isla, y no sólo la actividad azucarera. Describió sus vegas (en Cuba son las tierras dedicadas al cultivo del tabaco, que era una actividad económica fundamental de los hacendados cubanos), los hatos y haterías (territorio destinado a la cría de ganado), los monteros y las monterías (caza de animales y establecimientos cuya función principal era la corta y explotación de las maderas preciosas de la isla), y localidades como Mantua, en la zona más occidental, Consolación y Pinar del Río. En el romance "El montero de la sabana" quiso representar, a través de la lucha por el amor de una mujer entre dos hombres, los enfrentamientos que existían entre diferentes actividades económicas; por eso, uno de ellos era un veguero de los Martínez, la vega más rica de toda la isla, situada en la zona de Pinar del Río, y el otro era un montero; la mujer se casó con el primero. Sin embargo, del Monte obvió todavía, en la medida de lo posible, la descripción de los ingenios, para intentar no transmitir la idea de que la producción de azúcar era la base económica de la isla.

Todo esto lo combinó a la perfección con la descripción de la naturaleza "salvaje" y "no culturizada" aún de la mayor de las Antillas: la sabana, el bosque cubano, ríos como el Cayaguatege, que pasa por Guanes, en Vuelta Abajo (parte occidental de la isla de Cuba), y el Sansueñas; las tormentas huracanadas, árboles como la seiba, el jagüey (bejuco moráceo) y los guayabales (HERREA DÁVILA, 1833: 37-38, 42-45 y 64-66). El mar, como parte esencial de este territorio, pues es una isla, fue descrito por del Monte en el romance "El himno del navegante". En una variante de esta línea hay que enmarcar dos poemas de los que aparecen en Rimas Americanas: "La patria" y "A un joven poeta en su partida para Ultramar", donde comparó la exuberante naturaleza de la isla de Cuba con la aridez y el frío de las tierras de Castilla y la Sierra de Guadarrama, así como de otros lugares de Europa (HERREA DÁVILA, 1833: 37-38, 42-45 y 64-66).

En esta misma línea de defensa de los principios de ese sistema económico, que tenía como fundamento el crecimiento a través del aumento de 
la productividad, se entiende la crítica al juego y a los ratos de ocio, ya que esto significaba una pérdida de productividad. Por eso trató de introducir, a través de la poesía, una escala de valores donde el juego se consideró un "vicio" a eliminar en cualquier sociedad que se preciase (HERREA DÁVILA, 1833, p. 101-103).

A partir de la desaparición de la Academia de Literatura en 1834, Cirilo Villaverde, José Jacinto Milanés, Ramón de Palma y Plácido continuaron la estela que había marcado del Monte en la poesía y, por eso, dedicaron una gran cantidad de su producción a describir la naturaleza y el paisaje de la isla, perfeccionando las imágenes creadas anteriormente. En estas representaciones Milanés introdujo una gran cantidad de provincialismos cubanos (MILANÉS, 1965, p. 21-23, 46-48 y 50-52; MANZANO, 1837, p. 17-31; PALMA, 1861). Este autor y Ramón de Palma, siguiendo a del Monte, describieron el campo en relación a las actividades económicas que en él se desarrollaron. Dedicaron una serie de poemas a las actividades del montero, al que volvieron a retratar, como antes lo había hecho del Monte en Rimas Americanas, como un personaje solitario, equivalente al caballero medieval europeo y que venía a representar a una especie de héroe romántico, desdichado en amores, con el que se identificaba la nación que se empezaba a esbozar. Sin embargo, Milanés introdujo una novedad con respecto a lo hecho hasta entonces, y es que centró gran parte de sus esfuerzos poéticos en describir otra actividad económica del campo cubano, el trabajo en los cafetales y en los ingenios, los dos grandes sectores productivos de la zona occidental de la isla. Iniciaba así una línea que continuaran en verso, y sobre todo en prosa, otros autores, como Anselmo Suárez Romero. El retrato de los cafetales, algo menos duro que el de los ingenios, pues el trabajo del esclavo no era tan penoso, como explicó después Suárez Romero, no lo hizo mediante la descripción física de esta actividad económica, como hasta entonces había ocurrido, sino a través de la esclavitud (sobre todo de la figura del esclavo), que era uno de los elementos más característicos del ingenio y de los cafetales, y uno de los mayores impedimentos para el desarrollo del sistema liberal en la isla; por este motivo Milanés criticó la esclavitud, aunque todavía lo hizo de una forma bastante romántica. Centró sus ataques en los inmensos castigos corporales que recibían estos esclavos, el peor de todos el "boca abajo" (MILANÉS, 1865). Dio una esperanza al esclavo, el cimarronaje, como única forma de vivir como una persona con entidad propia, aunque en la proscripción (MILANÉS, 1865, p. 112-115; 123-128). Los esclavos, en esa sociedad liberal naciente, no eran considerados personas sino cosas $\mathrm{y}$, por eso, Milanés se recreó, en su obra "Negro Alzado", describiendo cómo el 
niño blanco usaba al pequeño hijo de un negro del cafetal como "muleque" o mascota para jugar:

IA las puertas del bohio/ sentado está el mayoral/ [...] Su hija mayor, con un peine/ negro alisándole va/ aquella gran cabellera/ [...] Dos chiquillos cerca de ella/ con un negrito, a la par/todos tres desnudos, juegan,/ retozan, gritan, se dan/y cada vez que el negrito/ amenaza a algún rapaz/ el gran manatí del padre/ que los mira retozar/ levanta en su tierna espalda/ doloroso cardenal/... (MILANÉS, 1865, p. 112-115).

Posteriormente, otros autores de la tertulia de del Monte dedicaron a esta cuestión, en la misma dirección, obras completas, como Cecilia Valés, de Cirilo Villaverde, Autobiografía de un esclavo, de Juan Francisco Manzano y Sab, de Gertrudis Gómez de Avellaneda.

En esta sociedad en construcción que quiere pintarnos el grupo de del Monte, el trabajo, como motor del desarrollo económico, era la forma de conseguir riqueza y prosperidad y, por eso, lo consideraron un valor que dignificaba, mientras que la ociosidad y el juego, como elementos que suponían una pérdida de productividad, fueron mal vistos. Por eso se despreció a los "vagos" (entendiendo por tales al mendigo, la prostituta, el expósito, el borracho, el bandido), que estaban al margen de la sociedad, que eran "despojos" de esa sociedad. También por este motivo fueron múltiples los intentos de los autores del grupo por fomentar el desarrollo de las profesiones manuales, realizadas en Cuba hasta ese momento sólo por personas de color, y a las que los blancos consideraban una deshonra dedicarse, por muy pobres que fueran; ellos, con sus discursos, trataron de convertir estos trabajos en honrados para la gente blanca pobre, como había sucedido en el mundo protestante. También se imaginaron en sus poemas a los blancos pobres trabajando en el campo, a través del arriendo de tierras a los ricos hacendados (MILANÉS, 1965).

Estos "valores" debían ser inculcados como norma, para lo cual se valieron de la religión. Por eso, una de las características que le dieron estos autores a esa sociedad ideal que recrearon fue la de ser católica, pues entendieron que la religión, usada correctamente, era un instrumento para introducir y legitimar los valores del sistema liberal, como habían hecho los protestantes en Europa (VALDÉS, sin año). El Dios de estos autores, también el de Rosa Sandoval en Cecilia Valdés, era piadoso, pero a la vez vengativo, un Dios que exigía amor al trabajo, honor en el hombre y la castidad y dedicación a su familia en la mujer; una religión que criticaba el adulterio, la prostitución y 
el juego, pero que, sin embargo, no los combatía enérgicamente pues eran válvulas de escape que permitían mantener un sistema insostenible de otra manera (MANZANO, 1838, 1839; SUÁREZ ROMERO, 1880).

La salvaguarda de esos principios liberales también supuso la defensa de un sistema de gobierno liberal, como el que se empezaba a implantar en la península, en la isla de Cuba. Por eso, Plácido amplió una de las líneas que del Monte había esbozado muy someramente en el periodo anterior: la de los poema favorables al desarrollo de una monarquía liberal, donde se criticaba la actuación de Fernando VII y se ponían nuevas esperanzas en la reina regente y la heredera del trono (VALDÉS, sin año). No obstante, para estas fechas, finales de 1836, el grupo era consciente de que desde la metrópoli no se pretendía trasladar el sistema de gobierno liberal a la mayor de las Antillas y, además, los principios de identidad que se proponían desde la península no incluían las reclamaciones que se hacían desde La Habana y otras localidades del territorio antillano. Por eso, en la construcción de la identidad que estaba elaborando el círculo en torno a del Monte, aunque seguían manteniendo la necesidad de extender a la isla la forma de gobierno liberal, comenzaron a utilizar la división criollo-peninsular, asimilando criollo a identidad cubana y peninsular a identidad española. Para ello, en sus obras, los malos tratos a los esclavos eran realizados por los comerciantes de negros, peninsulares, y una vez en el ingenio por los mayorales que, según los describieron posteriormente estos autores, generalmente eran peninsulares, pero no por parte de los dueños de los ingenios, que identificó con los cubanos criollos. Estos autores también contribuyeron a dibujar una escala social donde los cubanos criollos fueron situados por encima de los peninsulares (SUÁREZ ROMERO, 1880).

\section{CONCLUSIÓN}

Las obras Cecilia Valdés, de Cirilo Villaverde, Francisco, de Anselmo Suárez Romero, El Conde Alarcos, de José Jacinto Milanés y Matanzas y Yumurí, de Ramón de Palma, fueron la expresión más acabada del concepto de identidad que estaba creando el grupo de del Monte, distinta y contrapuesta, en muchos aspectos, a la española. No obstante, esta nítida delimitación fue fruto de un proceso de construcción literario anterior, liderado por del Monte, a través del cual fueron perfilando varios conceptos de comunidad, lo que da una idea del carácter artificial del mismo. Del Monte, en un principio, había pretendido construir una comunidad imaginada que incluyera a todo el territorio que aún se conservaba del antiguo Imperio español, con centro en La Habana y dominada por el grupo de hacendados que lo sustentaba 
(el de las familias Aldama, Alfonso, Arango y Soler). Pero, paralelamente, desde la península, la oligarquía castellana había iniciado su propio proceso de elaboración cultural, que fue el que finalmente se abrió paso, a pesar de las reticencias desde La Habana y otros lugares de la propia metrópoli. Ante este bloqueo, del Monte y los suyos pidieron que se integraran en la estructura castellana las peculiaridades del proyecto de su facción en términos de igualdad. Desde el otro lado del Atlántico tampoco se cedió a este deseo, por lo cual el círculo de intelectuales habanero centró sus esfuerzos en convertir esa cultura en la de toda la isla de Cuba, aunque todavía con fuertes lazos de unión con la que se estaba implantando en la península. Fruto de este largo proceso, del Monte terminó esbozando un nuevo concepto de "comunidad imaginada": Cuba, y Cirilo Villaverde lo sancionó a través de su obra. El valor del texto de Villaverde también radica en el poder documental de las descripciones del mundo del ingenio y de la esclavitud que en el se realizan.

\section{The color of the Skin in the Construction of Cuban Identity}

AвSTRACT:The aim of this article is to research the identity project built by the Cuban liberal autonomists' group during the nineteenth century. This faction was composed by intellectuals and members of the sugar Havana oligarchy. Their purpose was to look for a more advantageous position for the island of Cuba and the Overseas territories in the frame of the Spanish liberal state in construction throughout the nineteenth century. Due to the censorship, this group could not use the political speech to get this objective, which made that they had to look for an alternative way to express their ideas; literature transformed by this way into its main instrument. KeYwords: literature, Cuba, slavery, autonomy, identity

\section{REFERÊNCIAS}

AGUILERA MANZANO, J.M. La formación de la identidad cubana (la polémica Saco-La Sagra). Sevilla: CSIC, 2005.

AGUIRRE, Y. Leonardo Gamboa y la juventud cubana de su tiempo. Revista de la Universidad de La Habana, n. 2, pp. 147-161, 1986.

ÁLVAREZ GARCÍA, I. La obra narrativa de Cirilo Villaverde. La Habana: Letras Cubanas, 1984.

ÁlVAREZ JUNCO, J. Mater Dolorosa: la idea de España en el siglo XIX. Madrid: Taurus, 2002. 
ANDERSON, B. Comunidades imaginadas. Reflexiones sobre el origen y la difusión del nacionalismo. México: Fondo de Cultura Económica, 1993.

ANDERSON, B. Comunidades imaginadas. Reflexiones sobre el origen y la difusión del nacionalismo. México: Fondo de Cultura Económica, 1993.

ANDERSON, B. The goodness of nations. In: VAN DER VEER, P.; HARTMUT, L. (Eds.). Nation and Religion: Perspectives on Europe and Asia. Princeton: Princeton University Press, 1999.

ARCHIVO General de Indias, Cuba, leg. 761B, 763, 773, 774, 775, 776, 2057; Ultramar, leg. 138, 139.

BACHILLER Y MORALES, A. Apuntes para la historia de las letras y de la instrucción pública en la isla de Cuba. La Habana: Cultural, v. 1, 2 y 3, 1936.

BARRERA, P. The Black Protagonist in the Cuban Novel. Andover: University of Massachussets Press, 1979.

BARRERO, A. Un comentario del siglo XX a una novela cubana del siglo XIX: $\mathrm{La}$ joven de la flecha de oro. Santiago, n. 42, p. 209-218, 1981.

BATISTA VILLAREAL, T. Catálogo de publicaciones periódicas cubanas de los siglos XVIII y XIX. La Habana: Biblioteca Nacional José Martí, 1965.

BENICHOU, P. Creación poética en el romancero tradicional. Madrid: Gredos, 1968. BENICHOU, P. La coronación del escritor, 1750-1830. Ensayo sobre el advenimiento de un poder espiritual laico en Francia moderna. México: Fondo de Cultura Económica, 1981.

BLOCH, M. Pour une histoire compare des societés européennes. Revue de Synthèse Historique, n. 46, p. 15-50, 1928.

BUENO, S. Esclavitud y relaciones interraciales en Cecilia Valdés. Revista de la Biblioteca Nacional José Martí, n. 77, p. 43-68, 1986.

BUENO, S. Historia de la literatura cubana. La Habana: Ministerio de Educación de Cuba, 1963.

BUENO, S. Temas y personajes de la literatura cubana. La Habana: Unión-Ensayo, 1984.

BUENO, Salvador. Cirilo Villaverde y su novela máxima. Revista de la Biblioteca Nacional José Martí, n. 38, p. 43-67, 1986.

CALCAGNO, F. Diccionario biográfico cubano. Nueva York, 1878, v. 1, 2.

CALLAHAN W. J. Iglesia, poder y sociedad en España, 1750-1874. Madrid: Nerea, 1989.

CASTELlANOS, José F. Del Monte y Villaverde en Cecilia Valdés. Revista de La Habana, junio de 1947, p. 3-16;

CHATTERJEE, P. A Brief History of Subaltern Studies. En International Enciclopedia

José María Aguilera Manzano. El Color de LA PIEL EN LA CONSTRUCCIÓn DE LA IDENTIDAd CUBANA 
of the Social and Behavioral Sciences, Londres, v. 3, p. 1537-1541, 2000.

CONNOR, W. Ethno-Nationalism: The Quest for Understanding. Princeton: Princeton University Press, 1994.

COOPER, F. Colonialism in Question. Theory, Knowledge and History. Los Ángeles: University of California Press, 2005.

COULTHARD, G. R. Raza y color en la literatura antillana. Sevilla: Escuela de Estudios Hispanoamericanos, 1958.

DANIELS, C. y KENNEDY, M. Negotiated empires: centers and peripheries in the Americas, 1500-1820. Nueva York: Routhledge, 2002.

DESCHAMPS CHAPEAUX, P. Autenticidad de algunos negros y mulatos de Cecilia Valdés. La Gaceta de Cuba, n. 81, p. 24-27, 1970.

EAGLETON, T. Marxism and Literary Criticism. Metheun, Londres, 1976.

ESPAGNE, M. y WERNER, M. (eds.). Transferts: les relations interculturelles dans l'espace franco-allmand (XVIIIe et XIXe siécle). París : Editions Recherche sur les civilisations, 1988.

FERNÁNDEZ VILLAURRUTIA, R. Para una lectura de Cecilia Valdés. Revista Cubana, n. 31, p. 31-43, 1957.

FONTANA, J. La crisis del Antiguo Régimen 1808-1833. Barcelona: Crítica, 1979.

FONTANA, J. La quiebra de la monarquía absoluta 1814-1820. Barcelona: Ariel, 1971.

FRADERA, J.M. Colonias para después de un imperio. Barcelona: Ediciones Bellaterra, 2005.

FRADERA, J.M. Gobernar colonias. Barcelona: Península, 1999.

FRIOL, R. La Cecilia Valdés de La Siempreviva. Revista de la Biblioteca Nacional José Martí, n. 73, p. 43-52, 1982.

GELLNER, E. Nacionalismo. Barcelona, 1998.

GONZÁLEZ DEL VALLE, J.Z. Amar o morir y Amor o dinero. El Álbum, 1838.

GONZÁLEZ, R. Contradanzas y latigazos. La Habana: Letras cubanas, 1983.

GONZÁLEZ, R. Para una lectura historicista de Cecilia Valdés. Revista Casa de las Américas, p. 84-92, 1981.

GRACIA DE ALDRIDGE, A. Two Latin American Theorists of the Historical Novel. Clio, n. 4 , p. 183-199, 1975.

GUEVARA, G. R. Inexacting Whiteness: blanqueamiento as a Gender-Specific Trope in the Nineteenth Century. Cuban Studies, n. 37, p. 105-128, 2006.

HAYES, C. Nationalism: a Religión. New York, 1960.

HENRÍQUEZ UREÑA, M. Panorama histórico de la literatura cubana. La Habana: Editorial Arte y Literatura, 1978.

Hist.R., Goiânia, v. 16, n. 1, p. 233-257, jan./jun. 2011 
HERNÁNDEZ AZARET J.C. Los personajes femeninos en Cecilia Valdés. Santiago de Cuba: Dirección de Información Científico Técnica, 1983.

HERNÁNDEZ AZARET, J.C. Los personajes femeninos en Cecilia Valdés. Santiago de Cuba: Dirección de Información Científico Técnica, sin fecha.

HERRERA DÁVILA, I. (compilador). Rimas Americanas. La Habana, 1833.

HOBSBAWM, E. Nation and nationalism from 1780. Barcelona: Crítica, 1992.

JACKSON, R.L. The black image in Latin American Literature. Alburquerque: The University of New México Press, 1976.

JENSEN, L. R. Children of Colonial Despotism. Press, Politics, and Culture in Cuba, 1790-1840. Tampa: University Press of Florida, 1988.

KANDIYOTI, D. (ed.). Gender and Nationalism. Nations and Nationalism, n. 6, p. 213-235, 2003.

KEDOURIE, E. Nationalism. Londres, 1960.

KOHN, H. The Idea of Nationalism: a Study in Its Origens and Background. Nueva York, 1944.

KUETHE, A. Cuba, 1753-1815: Crown, Military, and Society. Knoxville; University of Tennessee Press, 1986.

LAMORE, J.: Cecilia Valdés: realidades económica y comportamientos sociales en la Cuba esclavista de 1830. Revista Casa de las Américas, n. 12, pp. 41-52, 1978.

LAZO, R. La literatura cubana. México: UNAM, 1965.

LEANE, C. Cecilia Valdés: espejo de esclavitud. Revista Casa de las Américas, n. 15, pp. 19-25, 1975.

LLAVERÍAS, J. Contribución a la historia de la prensa periódica cubana. La Habana: Publicaciones del Archivo Nacional de Cuba, v. 1, 2, 1957.

LLORÉNS, V. El romanticismo español. Madrid: Editorial Castalia, 1989.

LUCKÁCS, G. The Historical Novel. Londres: Merlin Press, 1962.

MANZANO, J.F. La cocuyera. El Aguinaldo Habanero, 1837, p. 17-31.

MANZANO, J.F. El Sueño. El Álbum, octubre de 1838.

MANZANO, J.F. Existencia de Dios. La Cartera Cubana, junio de 1839.

MARTÍNEZ, U. Domingo del Monte y su tiempo. La Habana: Unión, 1997.

MARTÍNEZ, U. José Jacinto Milanés. La Habana: Unión, 1989.

MARX, K. El colonialismo. México D.F.: Grijalbo, 1970.

MILANÉS, J.J. Obras. Nueva York, 1965.

MITJANS, A. Historia de la literatura cubana. Madrid: Editorial América, 1918.

MONTE, D. Centón epistolario. La Habana: Imagen Contemporánea, v. 1-7, 2002. 
MONTE, D. Escritos de Domingo del Monte. La Habana: Cultural, v. 2, 1929.

MONTE, D. Exposición de las tareas de la Comisión de Literatura. Actas de la Sociedad Económica de La Habana, 1830.

MONTE, D. Exposición de las tareas de la Comisión de Literatura. Actas de la Sociedad Económica de La Habana, 1831.

MONTE, D. Guirnalda Cubana. El Puntero Literario, 1828.

MOREJÓN, N. Cecilia Valdés: Mito y realidad. Revista de la Universidad de La Habana, pp. 51-61, 1980.

MORENO FRAGINALS, M. Cuba-España, España-Cuba. Historia común. Barcelona: Crítica, 2002.

MORENO FRAGINALS, M. El Ingenio. Complejo económico social cubano del azúcar. Barcelona: Crítica, 2001.

MORENO FRAGINALS, M. La historia como arma y otros estudios sobre esclavos, ingenios y plantaciones. Barcelona: Crítica, 1983.

NAVARRO GARCÍA, J.R. Control social y actitudes políticas en Puerto Rico (18231837). Sevilla: CSIC, 1991.

PALMA, R. Matanzas y Yumurí. El Aguinaldo Habanero, 1837.

PALMA, R. Obras de don Ramón de Palma. La Habana: Imprenta del Tiempo, 1861.

PALMA, R. Pascua en San Marcos y El cólera en La Habana. El Álbum, 1838.

PICHARDO, E. Diccionario provincial casi razonado de voces cubanas. La Habana, 1849.

PRAKASH, G. Subaltern Studies as Postcolonial Criticism. American Historical Reiew, n. 99, pp. 1475-1490, 1994.

RIVAS, M. Literatura y esclavitud en la novela cubana del siglo XIX. Sevilla: Escuela de Estudios Hispanoamericanos, 1990.

ROMERO TOBAR, L. Panorama crítico del romanticismo español. Madrid: Editorial Castalia, 1994.

SAID, E. Cultura e imperialismo. Anagrama: Barcelona, 2001.

SAID, E. Orientalismo. Barcelona: Debolsillo, 2004.

SAID, E. Orientalismo. Barcelona: Debolsillo, 2004.

SÁNCHEZ, J.C. La sociedad cubana del siglo XIX a través de Cecilia Valdés. Cuadernos Americanos, n. 2, pp. 123-134, 1971.

STOLCKE, V. Racismo y sexualidad en la Cuba colonial. Madrid: Alianza América, 1992.

SUÁREZ ROMERO, A. Francisco. Novela cubana. Nueva York, 1880.

TORRIENTE, L. La Habana de Cecilia Valdés. La Habana: Imprenta de Jesús

Hist.R., Goiânia, v. 16, n. 1, p. 233-257, jan./jun. 2011 
Montero, 1946.

VALDÉS, G. Poesías de Plácido. Nueva York, sin año.

VILLAVERDE, C. Cecilia Valdés o la Loma del Ángel. Novela de costumbres cubanas. Nueva York: Imprenta de El Espejo, 1882.

VILLAVERDE, C. Cecilia Valdés. La Siempreviva, v.2, pp. 74-87, 1839 B.

VILLAVERDE, C. Engañar con la verdad. El Álbum, mayo de 1838B.

VILLAVERDE, C. Excursión a Vuelta Abajo. El Álbum, agosto, septiembre, noviembre de 1838A.

VILLAVERDE, C. La joven de la flecha de oro. La Cartera Cubana, mayo, julio, agosto, septiembre, noviembre y diciembre de 1840.

VILLAVERDE, C. Una cruz negra. La Cartera Cubana de marzo, mayo, agosto y noviembre $1839 \mathrm{~A}$.

VVAA. Cuentos cubanos del siglo XIX. Antología. La Habana: Editorial Arte y Literatura, 1975.

VVAA. Diccionario de la Literatura cubana. La Habana: Instituto de Literatura y Ligüística de La Habana, v. 1 y 2, 1984.

WALLERSTEIN, E. The Modern World System. Nueva York: Academia Press, v. 1, 1974.

WEBER, M. Estructuras de poder. Buenos Aires: Leviatán, 1985.

WILLIAMS, R. Marxism and Literatura. Oxford: Oxford University Press, 1977.

XIMENO, J. M. Papeletas bibliográficas de Cirilo Villaverde. Revista de la Biblioteca Nacional José Martí, n. 4, pp. 133-153, 1953.

YOUNG, R. J. La novela costumbrista de Cirilo Villaverde. México: UNAM, 1949.

YOUNG, R.J. La novela costumbrista de Cirilo Villaverde. México: UNAM, 1949.

YUVAL-DAVIS. Gender and Nation. Londres: Sage, 1997. 